\title{
Dapodo, imagem Xavante
}

\author{
SAMUEL LEAL \\ FRANCISCO ANTUNES CAMINATI \\ ALINE YURI HASEGAWA
}

\section{Resumo}

Este artigo trata das implicações políticas e culturais da produção audiovisual contemporânea dos índios Xavante das aldeias Wederã e Etenhiritipá, analisadas a partir da experiência dos autores na realização do registro filmado de um importante ritual de iniciação, o Danhono, ocorrido ao longo do ano de 2011. O objetivo é refletir sobre o modo como a produção de imagens técnicas é integrada ao ritual; o estatuto que a imagem técnica adquire localmente em meio a esse processo de apreensão e de apropriação de tecnologias estrangeiras; e a função e o papel do vídeo na mediação da cultura xavante com o mundo externo e com sua própria reprodução futura (diálogo entre gerações).

Palavras-chave: Xavante/Auwẽ Uptabi, imagem, memória 


\title{
Dapodo, Xavante image
}

\author{
SAMUEL LEAL \\ FRANCISCO ANTUNES CAMINATI \\ ALINE YURI HASEGAWA
}

\begin{abstract}
This article addresses the political and cultural implications of the contemporary Xavante audiovisual production at Wederã and Etenhiritipá villages. Taking as point of departure the authors's participation in the filmed record of an important rite of initiation, Danhono, occurred during 2011, the aim of the article is to reflect on: how the production of technical image is integrated into the ritual, the status that the technical image acquires locally amid this process of apprehension and appropriation of foreign technologies, and the function and the role of the video in the mediation between the Xavante culture and the outside world and with their own future culture reproduction (intergenerational dialogue).
\end{abstract}




\section{Introdução}

Os wapté estão sentados na porta de suas casas, com a cabeça baixa sob a esteira de palha de buriti, palmeira comum na região. Não podem olhar para frente, mas certamente podem ouvir os comentários e a comoção das pessoas que acompanham a ação do trio de homens que se aproxima. São os isapu'uwa, os furadores. Dois deles são velhos que cumpriram esse papel em iniciações anteriores, e vem acompanhando o isapu'uwa atual. Ele irá perfurar as orelhas dos wapté, que esperam ansiosamente por este momento. Isso será feito com a iteihi, uma agulha feita do osso da onça-parda, objeto transmitido por gerações em uma linhagem de furadores. Depois disso, os meninos irão usar o buruteihi, um pequeno cilindro de madeira atravessado nos lóbulos das suas orelhas. Por meio desse gesto do furador e do objeto introduzido por ele, que agora constitui parte de seus corpos, eles dão mais um passo em seu caminho para a vida adulta.

Esse momento, central na formação dos jovens Xavante $^{2}$, é parte do Danhono, ritual de iniciação dos meninos que acontece aproximadamente a cada 5 anos. Em 2011, as aldeias Etenhiritipá e Wederã, localizadas na T.I. Pimentel Barbosa ${ }^{3}$, estado do Mato Grosso, realizaram esse ritual. As duas comunidades, seguindo uma prática de mais de 20 anos (LEAL, 2012), decidiram documentar o ritual em todas as suas etapas para a produção de um vídeo documentário. Essa documentação foi realizada por uma equipe mista, composta por xavantes e por waradzút, e obedeceu as orientações do Warã ${ }^{5}$, o conselho tradicional formado pelos homens adultos.

O presente artigo procura, a partir dessa experiência compartilhada entre pesquisadores e realizadores, indígenas e não-indígenas, demonstrar a dimensão política do modo 
como os Xavante produzem imagens: sua função estratégica em uma trajetória de guerra-relação com um mundo estrangeiro. Uma resposta ao estrangeiro que depende da apropriação de uma tecnologia estrangeira.

No processo de documentação do ritual, a tecnologia que vem de fora é articulada com a própria cultura Xavante, por meio de sua incorporação tanto nos rituais quanto na vida cotidiana. Nesse processo, a técnica de produção e de registro audiovisual se torna um vetor de memória, a qual é registrada e arquivada, mas também reproduzida e transformada, ganhando contornos efetivamente políticos que dizem respeito à própria possibilidade de existência e de continuidade da reprodução da cultura Xavante.

No centro da discussão colocada pelo artigo está a transformação que a imagem sofre, pois é, simultaneamente, a concretização de uma de relação com o exterior - mediação de mundos - e de uma relação com o próprio núcleo da cultura Xavante - mediação de memórias e de tradições. Por um lado, ressalta-se o aspecto político mais amplo, voltado à luta pelos direitos das populações indígenas no contexto do Estado Brasileiro. Por outro, remete-se ao modo como as tecnologias de produção e registro são apropriadas localmente, e passam a integrar e a modificar as redes de relações locais.

Acompanhando e dialogando com o texto, são apresentados três vídeos realizados especialmente para essa ocasião, gravados na aldeia Wederã em novembro de $2012^{6}$. Os vídeos contêm depoimentos endereçados às mesmas questões que este artigo aborda e visam oferecer uma perspectiva local, direta e não-mediada pela linguagem escrita e acadêmica. $\mathrm{O}$ vídeo aparece, portanto, como via para superar as limitações que a linguagem escrita impõe para este diálogo.

\section{O furador e o filmador}

Na escola estadual da aldeia $W e d e r \tilde{a}^{7}$, onde realizamos a maior parte dos trabalhos de oficinas e de edição das imagens, existiam muitos cartazes espalhados pelas paredes com desenhos de coisas acompanhados de seus nomes escritos tanto em português como no idioma local (figura 1). Um deles mostra um jovem Xavante, provavelmente um padrinho da iniciação, chamados danhohui'wa, pintado com o corpo todo preto, um quadrado vermelho na barriga e um grande retângulo vermelho cobrindo as costas. O jovem está segurando uma câmera de vídeo, e a palavra dapotó'wa completa a composição. 


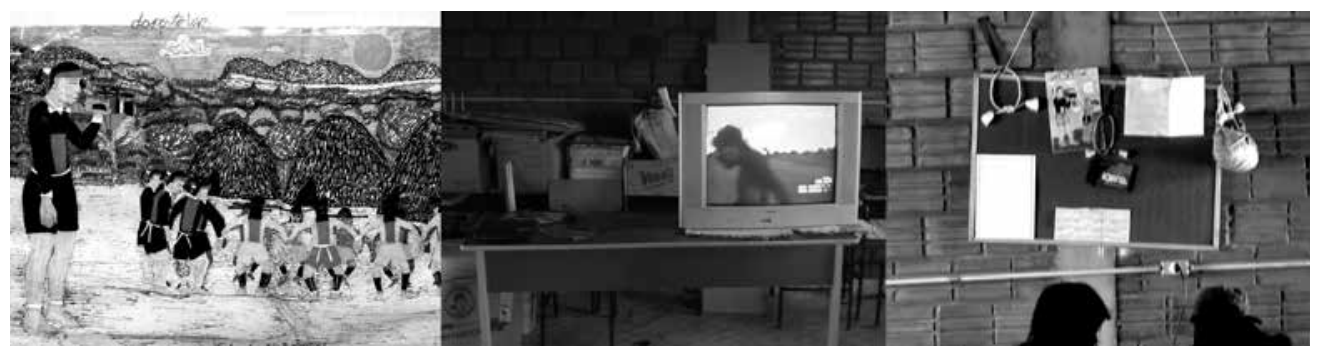

Tal palavra é uma referência à pessoa que manipula a câmera de vídeo, por sua vez conhecida como daptozé. O sufixo -wa fornece um caráter agentivo para o termo, baseado nas características invocadas pelo radical, enquanto o sufixo -zé realiza a substantivação dessas características, concretizando-as em um objeto. Nesse caso, o radical dapodo- refere-se a imagem. Sem os radicais -wa ou -zé, dapodo pode significar também fotografia, termo que ainda pode ser traduzido alternativamente como dahöibari ou dapodo iré. Dapodo também funciona como referência à imagem produzida pela câmera antes da edição, o material filmado bruto. Após a edição, tanto o vídeo finalizado quanto o suporte que o carrega, no caso a mídia do DVD, são chamados de rópodo, termo também utilizado como referência aos filmes que chegam da cidade ou são assistidos pela internet.

A formação do vocábulo dapotó'wa obedece ao mesmo processo de composição que opera no termo isapu'uwa, palavra que designa o furador. Isapu é o termo utilizado como referência à cerimônia de perfuração das orelhas dos meninos, assim como ao próprio gesto da perfuração com a agulha de osso iteihi. Assim, o sufixo - wa atribui à pessoa que o termo denomina uma agência associada às operações físicas e simbólicas da ação que ela executa, assim como à cerimônia das quais essas operações são o ato central. De maneira similar, o termo hö’wa é utilizado para designar os wapté enquanto moradores do hö. Aqui, o sufixo -wa atribui aos meninos uma designação relacionada ao local de moradia, que caracteriza seu lugar social na comunidade enquanto vivem ali. Na medida em que essa condição implica deveres específicos, existe também um aspecto de agentividade na formação da palavra. No termo dapotówa, as qualidades condensadas pelo radical dapodo- são atribuídos à pessoa que realiza a criação das mesmas. Novamente, a questão da agência ganha destaque, pois o dapotówa atua ativamente na fixação das imagens no suporte digital por meio na manipulação do objeto técnico que realiza a operação.
Figura 1

Desenho dapotówa; Decupando filmagens na TV; Quadro de avisos da Escola. Fonte: Acervo do Ponto de Cultura Apowẽ 
Todos os elementos que compõem o ritual de iniciação Danhono estão organizados em torno de procedimentos performáticos definidos. Dessas rotinas dependem o impacto social e psicológico que confere ao ritual sua eficiência: demarcar a consolidação de um processo de aprendizado e de formação. Isso ressalta a importância do uso e a função dos elementos materiais acima descritos na composição da rotina ritual. Esses objetos concretos ocupam um papel fundamental nas redes sociais articuladas em torno do ritual na medida em que promovem e movimentam relações, servindo como suporte e agente das mesmas.

No caso da furação, a agulha iteihi é um artefato familiar, transmitido entre gerações. É a perfuração da orelha por ela que legitima o potencial sexual desses jovens e reconhece seus direitos à vida adulta, embora a autorização para o exercício desses direitos ainda leve algum tempo. Tal gesto realiza uma transformação na sua identidade social por meio da intervenção nos seus corpos, a qual é marcada pelo buruteihi que deverão carregar nos lóbulos por toda a vida adulta.

Portanto, o isapu'uwa ocupa um dos papéis-chave do ritual. Ele é um dos portadores, por meio da agulha, do poder de transformar os wapté em ritei'wa, meninos em rapazes. Ele intervem nos corpos, primeiro com a iteihi e depois com o buruteihi. Assim, homem, osso e madeira formam um complexo de seres humanos e não humanos, dotado de uma agência inexistente em cada elemento separado. A própria formação social do menino xavante depende da intervenção desse conjunto.

Um procedimento análogo é realizado pelo dapotów $w a$, por meio do uso do objeto técnico daptozé. Homem e máquina constituem um conjunto que adquire uma dimensão transformadora que, por meio da ação de captura das imagens do ritual, atua sobre o conteúdo e sobre a realização da performance. Na medida em que é incorporado nos circuitos rituais, o vídeo os conecta a um espectro mais amplo. Por meio dele, a cultura Xavante passa a existir não só na relação entre as pessoas, e das pessoas com as técnicas tradicionais ou com as técnicas estrangeiras assimiladas localmente, mas também na relação com as imagens técnicas, e nas relações entre as pessoas e essas imagens técnicas ${ }^{9}$. Nesse sentido, o procedimento do filmador (dapotówa) é também complementar ao do furador (isapu'uwa) no contexto do ritual.

Se a associação homem-agulha-madeira tem a capacidade de fazer do wapté um ritei'wa, a associação homem-câmeraperformance também pode operar uma transformação, só que 
em outra escala. Homem e equipamento atuam em conjunto e de maneira inseparável do contexto cerimonial no qual assumem um papel fundamental. Constituem-se mutuamente, assim como a cerimônia é ao mesmo tempo constituinte dessa relação e constituída por ela. Finalmente, a associação homem, equipamento e ritual adquire uma capacidade agentiva transformadora que não existe para cada um deles separadamente. Aqui, a tecnologia produz o homem e a cultura na mesma medida em que homem e cultura produzem a tecnologia.

Se por um lado a relação da agulha com o furador já está consolidada culturalmente, a relação da câmera com o seu portador ainda passa por uma estabilização. $\mathrm{O}$ isapu'uwa realiza uma transformação corporal, social e biológica no contexto do ritual. Já a transformação operada pelo filmador ocorre pela amplificação do efeito da performance no espaço e no tempo: no espaço, na medida em que faz esses signos chegarem a outras aldeias e outros locais; e no tempo, na medida em que as imagens constituem uma memória física voltada para chegar às futuras gerações.

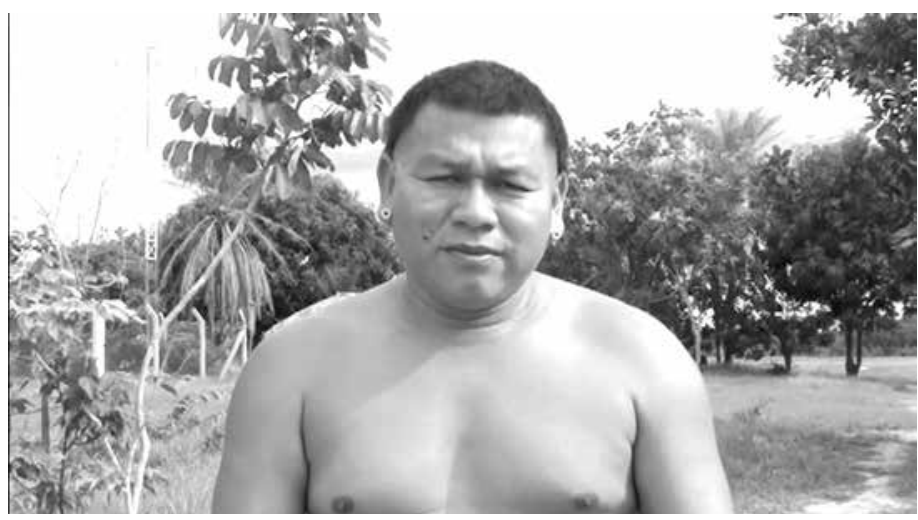

Aquilo que a câmera transmite ao seu operador passa a ser de uma qualidade diferente, na medida em que se torna também objeto de mediação de todo o grupo. O grupo estabelece linhas de subjetividade que fraturam o dispositivo audiovisual e as linhas de poder que o constituem. Dessa forma, o grupo subverte o uso da câmera quando coloca novos usos para ela, usos baseados na vida da aldeia. Por meio dessa subjetivação, a qual se dá na escala da comunidade, o indivíduo é inserido em uma série de procedimentos de regulação, e o potencial do uso da câmera passa a estar em uma zona de segurança para os interesses comunitários.
Figura 2

Vídeo 2: Caimi Waiassé. Fonte: Acervo do Ponto de Cultura Apowẽ

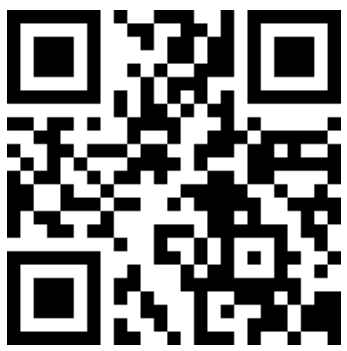

youtu.be/IogigsA-TDQ 
Nesse sentido, a função do filmador se torna cada vez menos estranha, se aproximando estruturalmente da condição social do furador. Na medida em que passa a ter uma função inteligível o vídeo é incorporado enquanto elemento de socialização local. Sua assimilação se torna viável à medida que o operador ganha uma posição social definida; e, na medida em que o operador pode ser localizado socialmente, o seu aparelho é domesticado.

\section{Xavantização do vídeo}

A mudança de contexto altera os limites do uso do equipamento, redefine suas funções. $\mathrm{O}$ investimento social sobre esse uso imprime uma marca profunda sobre o equipamento, que o insere em uma nova rede de socialidade, que contempla agentes humanos e não humanos, para a qual sua existência não havia sido pensada inicialmente.

Segundo Shohat e Stam (2006, p.148), o aparato do cinema compreende tanto uma base material (câmera, projetor, tela) quanto uma base imaterial (desejo, símbolos, repertório), conjunto que possibilitaria a experiência de identificação do espectador a "um tipo de sujeito transcendental" (METZ, 1982, p.49). Estendendo o argumento para a produção indígena, um novo aspecto deve ser levado em consideração, que é sua intenção cultural. Na produção indígena, estética, crítica e afirmação cultural constituem o discurso audiovisual em um mesmo plano de imanência, expressando por meio das imagens os desdobramentos cotidianos do uso da câmera. Trata-se de uma postura que, por um lado, é propriamente etnográfica, na medida em que elabora uma sistematização da própria cultura; por outro, aponta para possibilidades de generalizações estratégicas, com objetivos conscientemente políticos.

Um exemplo é o vídeo “Oió: Luta dos meninos" (2009), produzido por Caimi Waiassé (figura 2). Nele, a cena de abertura ganha todo o seu peso a partir de uma contingência de ordem técnica. A improvisação de uma lanterna amarrada na alça da câmera, solução encontrada para iluminar a cena noturna, resultou em foco de luz amarelado fixo no centro do plano, cuja intensidade não consegue preencher todo o quadro. Além disso, os próprios gestos que pintam na escuridão os pequenos e ansiosos meninos, que são preparados para lutar, possuem um grande apelo estético. Junta-se ainda à expectativa criada pela sequência narrativa da montagem, que introduz aos poucos o tema do vídeo, o ritual do qual as imagens constituem os momentos iniciais. 
Essa sequência reúne estética, crítica e afirmação política em um mesmo plano e não deve, como também em toda produção audiovisual política e socialmente minoritária, ser abordada por critérios exclusivamente técnicos. São constituídas também por determinantes sociais e culturais, na medida em que passam a ser incorporadas por redes de relações entre pessoas e grupos e contribuem para a catalisação dessas relações. Uma vez capturada pelas redes de socialização e de reprodução cultural de um grupo, essas tecnologias irão assumir uma outra forma cultural, adaptada localmente.

Assim, a documentação audiovisual dos rituais feita pelos próprios Xavante instaura uma linha de subjetividade dentro dispositivo cinematográfico (DELEUZE, 1989). Formalmente, tal documentação constitui um uso do aparato cinematográfico similar à catalogação imperialista dos territórios e dos povos dominados. No entanto, os objetivos são diametralmente opostos. A catalogação dos próprios costumes não tem função de controle, mas de memória. Os registros não saem do âmbito local para favorecer um controle externo, mas circulam interna e externamente com o objetivo de resolver o problema da afirmação e da transmissão cultural. Com isso coloca-se também a luta pelo território, uma vez que modo de vida e território são elementos que se constituem mutuamente.

Quando incorporam um objeto técnico como a câmera no complexo ritual e identitário, os Xavante exercem sua mediação, cultural e humana, sobre o processo de integração, modulando-o conforme seus objetivos e necessidades. A incorporação da câmera no ritual se dá por meio da reinvenção do equipamento e do seu operador em termos rituais. Podemos dizer, a partir de Deleuze (idem), que isso faz surgir linhas de fuga e de subjetivação que despertam um devir-agulha na câmera e um devir-xavante da imagem produzida pelos equipamentos técnicos. Assim, a atividade de auto-catalogação cultural é ao mesmo tempo resultado e combustível para o processo constante de auto-invenção dos Xavante por si mesmos.

\section{Memória como campo de ação política}

"As pessoas morrem, as imagens continuam". A partir deste fragmento de depoimento de Maurício Urawẽ (figura 3), extraído de um dos vídeos que dialogam com este artigo, está explícito um dos aspectos que o trabalho com tecnologias audiovisuais possibilita: o diálogo entre os vivos e os mortos, isto é, o potencial de reprodução incessante de imagens e de vozes gravadas, trazendo 


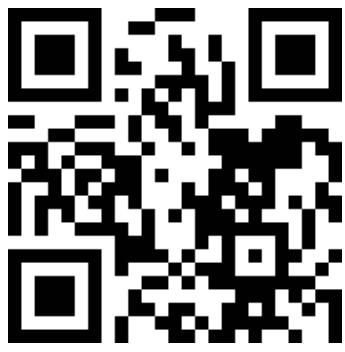

youtu.be/xpoRnU $U_{3} J Q U$

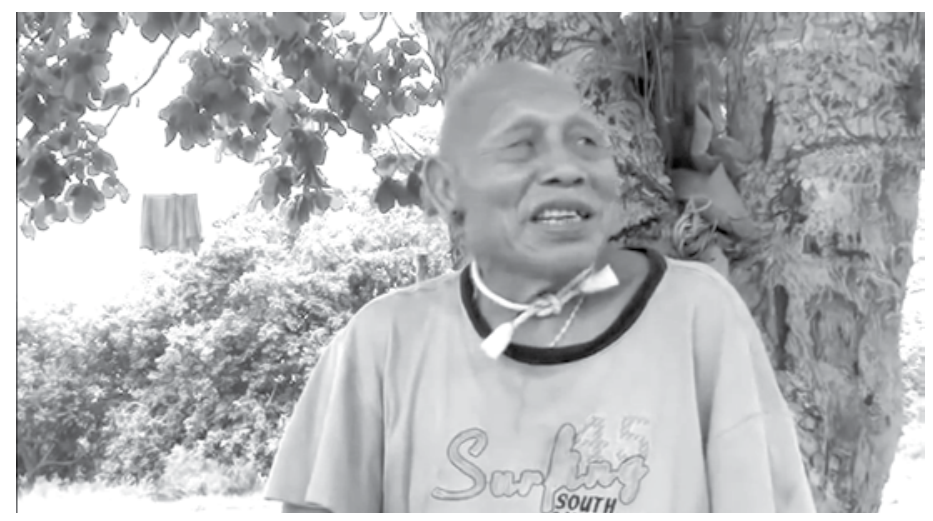

“vida" àqueles que não estão mais no "mundo de cá". É por isso que, ainda segundo o ancião, alguns não gostam de serem filmados ou terem suas vozes gravadas, já que as imagens retratam o que a pessoa vive quando "estava na Terra". São as memórias de alguém, de um tempo no passado.

Afora as discussões das implicações inerentes à cosmologia Xavante ${ }^{10}$ do uso das ferramentas audiovisuais, existem implicações políticas decorrentes do uso dessas tecnologias também para o trabalho com as memórias, as quais serão ressaltadas a seguir.

"Trazer vida" à memória, inserindo o passado - e os antepassados - na organização do presente enreda um movimento de análise do presente à luz do passado, comparativamente. Assim, o papel dessas tecnologias é expandido para muito além do que seria apenas o registro ou a representação, e abarca questões pedagógicas, identitárias e, sobretudo, estratégicas.

Pedagogicamente, ao tornar possível a visualização de tempos e de rituais passados por meio das imagens filmadas no presente, as gerações que se deixaram registrar assim ensinam aos mais novos como os antigos organizavam a vida social Se por um lado, o avanço do sistema capitalista impôs às gerações mais jovens o aumento das dificuldades de reprodução de um modo de vida baseado na relação não cindida do homem com a terra; por outro, o uso das tecnologias audiovisuais estrangeiras rompe a barreira temporal e espacial, tirando essa nova geração da solidão de serem indivíduos sem história e sem tradição, encorajando-os a continuar um projeto de vida baseado na coletividade e na tradição" .

Identitariamente, as imagens podem ser uma ferramenta de intensificação dos laços sociais. Em Wederã, é feito um uso interessante do vídeo nesse sentido. Durante a infância, os me- 
ninos xavante participam de uma luta ritual chamada Oió. Está habilitado a participar desse ritual todo menino que já conseguir ficar de pé com seu próprio equilíbrio e força, segurar firmemente com as mãos os objetos e que ainda não tenha entrado no hö. $\mathrm{O}$ ritual consiste em uma luta em que meninos de portes físicos parecidos e de clãs diferentes lutam entre si, devendo bater nas costelas e nas costas do adversário com o talo de uma raiz dura chamada oi’ó, que é cortada para a ocasião tomando a forma de um bastão. A luta continua até que um dos lutadores desista, ou que os adultos decidam que já houve luta o suficiente.

Existe grande investimento por parte dos pais na preparação dos seus filhos para esse ritual, na medida em que ele não só é uma importante ferramenta de educação em que valores como respeito, coragem e honra são reforçados, como também são atualizadas algumas relações e disputas entre as linhagens e os clã. Em uma pausa entre uma das oficinas de formação realizadas em Wederã, alguns adultos exibiram para as crianças um vídeo recentemente realizado por Caimi Waiassé, sobre esse ritual, já mencionado anteriormente. Durante a exibição, eram feitos comentários sobre trechos das lutas, assim como indicações sobre acertos e erros dos lutadores. As crianças observavam atentas enquanto os adultos se exaltavam reproduzindo os movimentos de um bom lutador, pausando e repetindo alguns trechos diversas vezes.

Essa ocasião demonstra de maneira prática as questões sobre a relação entre imagem e memória. O registro leva ao conhecimento de si, o que produz uma transformação, que acontece em dois sentidos: aponta para o passado, recuperando a consciência das próprias tradições, e aponta para o futuro, pois assimila tecnologias estrangeiras em um uso simbiótico com as necessidades locais, forjando estratégias calcadas na identidade étnica para o posicionamento crítico à cultura hegemônica. Finalmente, o ciclo se fecha com a transmissão das tradições para as novas gerações por meio desses registros feitos, no contexto das transformações em curso. Assim, a memória intensifica as marcas identitárias, uma vez que reforça os signos internos coletivamente compartilhados: danças, músicas, pinturas, alimentação, formas de falar e de agir, posturas corporais etc.

Estrategicamente, as memórias, ao reforçarem os laços sociais através de referenciais tradicionais - os signos coletivamente compartilhados -, funcionam também como agentes do futuro, uma vez que direcionam o olhar dos mais jovens para a reprodução do modo de vida tradicional, fincando raízes cada vez mais fortes, profundas e seguras em torno da ancestralidade. 
O debate sobre as memórias traz a todo momento a ideia das especificidades e das subjetividades individuais, mas sem deixar de considerar a base social e histórica de cada representação, de cada narrativa, de cada relato.

Assim, se cada narrativa ou relato é uma operação individual, essa ação é resultado da elaboração da experiência social, do próprio cotidiano. É, portanto, a transformação de sensações, impressões, vivências e costumes em narrativas possíveis através da racionalização da subjetividade e do inconsciente. $\mathrm{O}$ que significa trazer para o código do presente todo o passado e uma projeção sobre o futuro. O trabalho com a memória apresenta esse potencial revelador e ao mesmo tempo criador de identidades e subjetividades. Portanto, quando Caimi Waiassé, em outro dos vídeos que dialogam com este texto, fala de sua experiência com os vídeos e com os projetos realizados junto com os waradzú, ele mobiliza sua própria trajetória, que é individual, mas concomitantemente, ele abre o fio da memória e, amparado em seus antepassados e na força dessa tradição, põe em evidência eixos explicativos que vão além da racionalidade prática ocidental e capitalista. Transporta, assim, o intangível e o imaterial - a memória de um tempo que já se foi - para o presente, e acaba por projetar também um futuro.

Portanto, o trabalho com as memórias através dos vídeos (figura 4), além do potencial de transformação reveladora na própria subjetividade daqueles que produzem suas narrativas, também abre outro horizonte de emancipação: a pluralização da participação dos sujeitos nos eventos históricos, retirando o monopólio do protagonismo político e histórico das mãos de grupos hegemônicos. Leva-se, desse modo, para o campo da disputa política e do embate público versões subalternizadas

Sequência de imagens sobre uiwede dza darã (buriti preto), etapa do ritual de iniciação dos adolescentes Danhono. Fonte: Acervo do Ponto de Cultura Apowẽ da experiência cotidiana, evidenciando o conflito imanente no trabalho de "contar uma história". Assim, ao levar em consideração o simbólico, o subjetivo e o cultural no processo de reconstrução do passado - no próprio trabalho com as memórias, portanto - apresenta-se a potencialidade da emancipação, uma

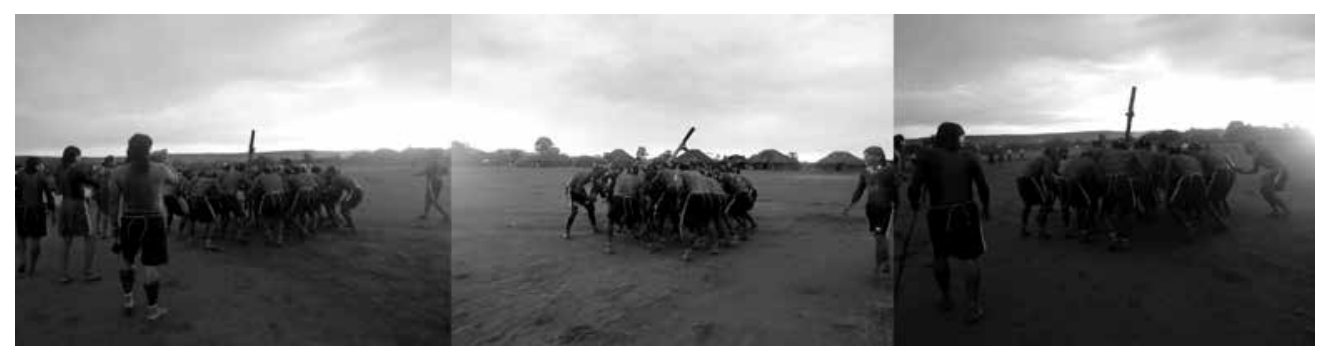




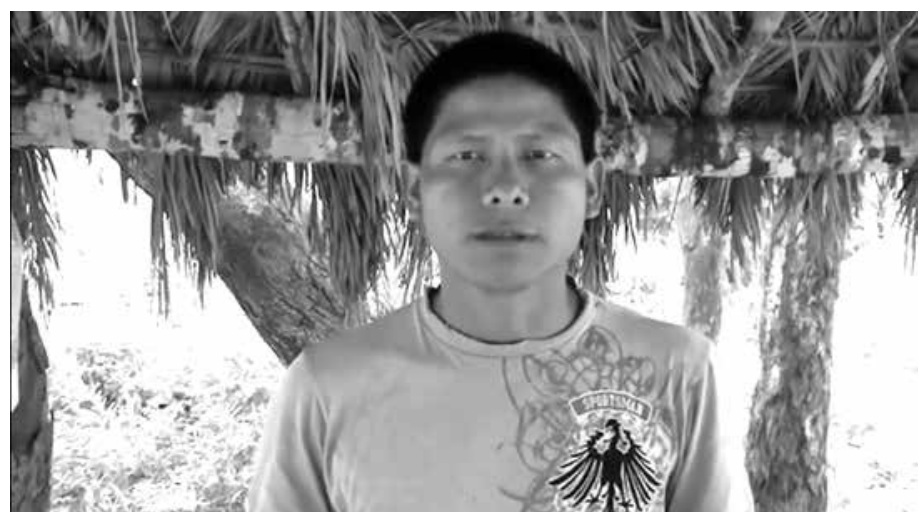

vez que os sujeitos deixam de ser atores do processo histórico e passam a narradores de si mesmos.

"Eles estão sempre lembrando para não esquecer". Este outro fragmento do depoimento de Maurício Urawẽ, sintetiza o potencial emancipador do trabalho com as memórias: o perigo do esquecimento dos rituais ou o pesadelo da perda da memória coletiva é, na realidade, o desaparecimento físico, real deles. Não se trata aqui de linguagem metafórica. Se as práticas sociais e as especificidades culturais determinam as idiossincrasias de uma comunidade, o esquecimento destas implica no próprio desaparecimento desta comunidade.

Assim, ao assistirem ou escutarem vídeos e gravações de seus antepassados - ou de si próprios em contextos anteriores - os Xavante analisam todas as mudanças pelas quais passaram desde o início do contato com os waradzú. Posicionam-se crítica e conscientemente a respeito do que foram e do que querem ser. Os velhos ensinam os jovens a darem continuidade aos rituais; enquanto os jovens registram os velhos para que as próximas gerações tenham a possibilidade de diálogo com o passado, uma base a partir da qual lançarão suas estratégias de reprodução social.

Ao apagar da memória a existência das diferenças, o capitalismo, através da modernidade, homogeneíza - por meio da violência, da repressão, do autoritarismo, da espoliação e da produção de miséria - as experiências e a própria "História", como se universalmente fizéssemos, todos, parte de um único movimento e de uma única racionalidade. Já que o esquecimento significa inexistência total ${ }^{12}$, o acesso à memória é a ferramenta a partir da qual se garante a existência, a permanência, a reprodução. O trabalho com as memórias constitui-se, portanto, como verdadeiro projeto de resistência à homogeneização.
Figura 5

Vídeo 3: Leandro Parinai'a.

Fonte: Acervo do Ponto de

Cultura Apowẽ

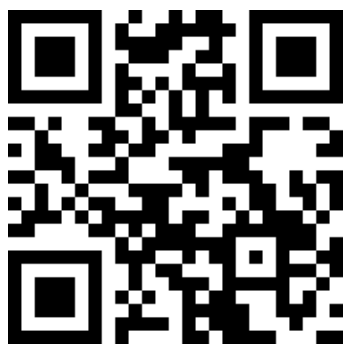

youtu.be/FfqfiFa3-iU 
Isso implica também na percepção de que somente a partir de uma gestão autônoma do território é possível reproduzir um modo de vida tradicional. Nas palavras de Leandro Parinai'a, que também aparece em um dos vídeos, "os rituais dependem do meio-ambiente" (figura 5).

Os avanços do capital pelo campo representam as principais ameaças à reprodução de modos de vida tradicionais, já que estas pressupõem relações sociais e modos de produção que não se limitam nem se enquadram no binarismo modernoocidental da cisão do homem com a terra, ou melhor, é justamente na simbiose da vida social com a terra que esses modos de vida se tornam possíveis. Toda a reprodução da vida Xavante - política, econômica, cultural, ecológica, alimentar - passa pela relação íntima estabelecida com seu entorno. A terra, ao contrário da visão moderna, não é algo que se domina e se subjuga. Tampouco é algo passível de se tornar mercadoria. Ela é o meio de produção de toda a vida e para onde toda a vida retornará. Sua concepção de mundo abarca o meio ambiente, não é cindida dele, e tampouco é estranha a ele. Desse modo, não se concebe um modo de vida baseado nas premissas ancestrais sem que haja um território e uma terra onde possam ser livres para viver desse modo, expressando cotidianamente a fusão de si com a terra. A memória, assim, ao remeter constantemente ao próprio território, como base para a reprodução da vida, reafirma continuamente a inescapabilidade da autonomia territorial. A imaterialidade da memória afirma suas bases materiais, suas raízes, no próprio território.

\section{Como lidar com o waradzú}

A experiência Xavante de apropriação de técnicas de produção de imagem precisa ser entendida em continuidade ao processo de integração definitiva dos Xavante à sociedade nacional brasileira, ao processo de pacificação do branco. Mais precisamente, a uma estratégia de liberdade traçada a partir de um sonho, que orientou um projeto de autonomia e de resistência diante desse processo inexorável de integração que possui como um de seus fundamentos o conhecimento do Outro e a apreensão de suas tecnologias para mediar essa relação de alteridade.

Referimo-nos aqui ao sonho do Cacique Apowẽ, que é considerado o líder desse processo. Foi ele quem negociou o contato definitivo entre seu povo e o $\mathrm{SPI}^{13}$ no final da década de 1940, quando percebeu que a estratégia de guerra não era mais sufi- 
ciente para evitar o avanço de fronteira que colocava em risco a continuidade do povo Xavante, de seu território e de seu modo de vida. Nos anos 1950, Apowẽ recebeu o antropólogo americano David Maybury-Lewis, o primeiro a realizar uma etnografia sobre seu povo, que deu origem ao clássico da Antropologia "A Sociedade Xavante" (MAYBURY-LEWIS, 1984).

No final dos anos 1970, preocupado com a degeneração ambiental e com o modo de vida tradicional pela intensificação do contato com a cultura e a economia waradzú, Apowẽ elaborou uma estratégia para proteger seu povo e sua cultura. Orientado por seus sonhos, e antecipando-se ao pior cenário possível que poderia decorrer da expansão modernizadoracolonizadora ao oeste ${ }^{14}$, enviou 8 de seus netos para estudar em cidades de São Paulo e de Goiás. O objetivo era que aprendessem a língua e os modos de vida dos waradzú para que, quando se tornassem adultos, tivessem condições de liderar os Xavante para que continuassem a ser Auwẽ Uptabi, ou seja, povo verdadeiro - povo de verdade.

Alguns destes jovens chegaram a ficar até 10 anos na cidade, e quando concluíram sua formação na cultura externa - como se referem atualmente a essa experiência - foram fundamentais para a luta pela demarcação dos territórios Xavante nos anos 1980, tiveram participação destacada nos movimentos políticos realizados durante a Constituinte ${ }^{15}$ para a consolidação dos direitos dos povos indígenas do Brasil e hoje são líderes em diferentes aldeias.

A estratégia de Apowẽ era bastante interessante: para continuarem sendo verdadeiros, precisavam conhecer a cultura que os acossava e os ameaçava. Era preciso saber como o inimigo convertido em vizinho pensava, quais eram seus valores, como se relacionava com o mundo. Era preciso saber operar em sua lógica para que fosse possível lidar com ele e para conseguir processar de maneira positiva a inevitável transformação decorrente e inerente à opção da via pelo contato pacífico.

O que mais chama atenção nesse processo é que não se trata de uma tentativa de "inclusão" no mundo dos brancos, mas da continuação de um processo de conhecer para enfrentar, da elaboração e da execução de uma estratégia de liberdade e de autonomia em relação a uma convivência imposta e incontornável. Uma resistência ao avanço do waradzú que passava pelo conhecimento profundo do mundo e da cultura waradzú, e pela apreensão e apropriação de algumas de suas tecnologias. Se a língua e a escrita foram as primeiras tecnologias apreendidas, assim que reconheceram a importância 
e aos processos produtivos que elas disparam - as habilidades que são a contrapartida humana a seu funcionamento (STRATHERN, 1999) - se tornem ainda mais valiosos.

A experiência com tecnologias de produção de imagem, que pode mesmo ser considerada uma das pioneiras entre os povos indígenas do Brasil, acaba fornecendo um modelo para novas experiências de apropriação tecnológica. A chave fornecida é da construção de uma linguagem que permita a aplicação das tecnologias para resolução do problema externo (a mediação com o Estado, com a sociedade nacional e do avanço da fronteira de produção do capitalismo) e, ao mesmo tempo, de seu aproveitamento para a resolução de problemas internos. No caso do vídeo, estes últimos referem-se à transmissão cultural e à gestão da memória coletiva, sua aplicação para o estabelecimento de um diálogo entre gerações, um diálogo que, no limite, ocorrerá entre os antepassados e as futuras gerações. E, em outras frentes que a evolução da relação com o exterior impõe, apontam para a aplicação de técnicas de gestão e de controle territorial, que permitam a preservação da integridade da comunidade a partir da preservação da integridade do território.

\section{Conclusão}

"Nós, Xavante, não resistimos a essas mudanças. Não conservamos nossas ideias, nossos pensamentos. Mesmo assim, a gente tem uma ligação muito forte com nossas raízes". Essa frase enunciada também pelo ancião Maurício Urawẽ, apesar do tom pessimista à primeira vista, ressalta o aspecto dialógico da assimilação do aparato audiovisual. É fruto da enunciação de um discurso dos Xavante sobre si, resultado do processo discutido nesse artigo. É um discurso que, se não é plenamente híbrido, na medida em que permanece Xavante, comporta aspectos não locais que, ao serem assimilados localmente, passam a constituir identidade Xavante transformada, adequada ao contexto político-cultural contemporâneo.

A maneira como foi formado o repertório audiovisual das comunidades em Pimentel Barbosa a partir da chegada dessas tecnologias é muito expressiva acerca do investimento cultural dedicado à questão. Vídeos com produções indígenas realizadas no contexto do Vídeo nas Aldeias ${ }^{16}$ também começaram a circular, a partir do envolvimento com o projeto. Em pouco tempo, essas produções já eram referência. Os primeiros usos do vídeo 
entram em um registro local de produção e de circulação, e apenas em um segundo momento dirigiram o olhar para fora.

Isso, no entanto, não é um processo espontâneo, mas sim fruto de um investimento intenso das comunidades, que se reflete na natureza coletiva que constitui a produção audiovisual em Wederã. Ou seja, os Xavante dessa aldeia não buscam aprender a fazer vídeos para se tornarem waradzú. Pelo contrário, reforçam nos vídeos uma diferença fundamental para que se possa viabilizar uma comunicação executada nos seus termos.

Com isso, tradição, memória, cultura e política ganham uma fluidez que torna inútil qualquer tentativa de observá-las enquanto categorias mais ou menos definidas. Elas passam a fazer parte de um processo de investigação e de reprodução, de ensinamento e de aprendizado, de invenção e de reinvenção, que é colocado em movimento pelo surgimento da figura do cineasta local que dirige seu olhar para os costumes de seu povo. Colocar tal processo em foco teve como objetivo a produção de um conhecimento que comporta a reflexão Xavante que o caracteriza.

Assim, o processo de produção de um vídeo acaba por constituir uma exegese cultural feita pelo grupo sobre si mesmo. O passado não é mobilizado em simples continuidade com o presente, mas em uma articulação de termos que potencializa agenciamentos futuros. E o presente é transformado pela natureza reflexiva do processo, recuperando uma certa continuidade entre passado, presente e futuro em torno do que se entende por identidade Xavante. É, porém, uma identidade que possui uma fluidez que se movimenta na dialética estabelecida entre fixidez e circulação, recepção e assimilação dos signos culturais. Imagem fixa e performance social se alimentam mutuamente, complexificando a dinâmica cultural expressa nas relações entre as pessoas envolvidas no processo.

A produção audiovisual é uma das diversas formas de expressão dessa perspectiva de luta. Nesse caso, a sujeição do indivíduo a um conjunto de exigências garante para o grupo que o uso do equipamento esteja de acordo com os objetivos determinados pela comunidade. Assim, o perigo inerente à transformação cultural implicada na adoção de novas práticas é neutralizada em favor da tradição, da qual a transformação passa ser a própria expressão. Mais que isso, o modo com que se dá a transformação é o que define a própria tradição (SAHLINS, 1997).

Para a efetividade da afirmação de uma identidade étnica, assim como dos desdobramentos políticos dessa pos- 
tura, é fundamental para a produção audiovisual Xavante, e indígena em geral, a colocação de um ponto de vista, de uma maneira de olhar. A capacidade de discutir com a sociedade brasileira os termos desse olhar sobre si é decisiva para seu futuro político-cultural. É nessa direção que aponta a estratégia de Apowẽ.

Coerente com tal estratégia, o uso Xavante das técnicas do vídeo realiza uma indigenização do dispositivo cinematográfico: a reinvenção de seu uso pela subjetivação das linhas de poder que por muito tempo identificaram suas imagens e discursos com o dispositivo imperialista colonial. A partir de uma escolha consciente por valores tradicionais, realizam um atualização da técnica, ampliam as possibilidades do seu uso. Como estratégia de heterogeneização do discurso sobre a identidade, os vídeos indígenas estabelecem uma interlocução cultural no campo onde praticamente qualquer luta política contemporânea deve entrar: os meios de comunicação e as mídias de massa; o conhecimento técnico, a informação e seus circuitos e redes de circulação.

$\mathrm{O}$ vídeo se torna simultaneamente vetor de transmissão e de transformação cultural. A observação da maneira correta de executar os rituais resulta na beleza da performance. Seu registro é a garantia de que tal beleza possa superar a fugacidade da memória, intensificada por um contexto de aceleração das transformações. Porém, o registro também carrega algo fugaz, que reside na parcialidade e nas limitações dos olhares do aparelho, do operador e do espectador. A circulação do registro é a possibilidade que correção e beleza permaneçam signos da identidade desejada localmente.

Com isso, os Xavante modulam os impactos do contato com a sociedade brasileira de maneira estratégica, criando as condições para a perpetuação de seu modo de vida. Permanecem Xavante exatamente na medida em que se abrem para a viabilização de trocas culturais que, na medida do possível, ocorrem a partir de seus próprios termos. Ao realizarem isso por meio de parcerias produtivas, se posicionam também como produtores de conhecimento e discurso. Ao capturarem agentes externos em suas redes, e deixarem-se capturar por outras redes, inserem-se ativamente nesses circuitos e influenciam suas produções.

Esse texto e o trabalho de cooperação que o fundamenta, é resultado de uma dessas capturas. 
1. Wapté é o nome dado à geração de meninos que está sendo formada no ritual em questão. Essa nomenclatura faz parte de um sistema mais complexo de organização e classificação social Xavante, descrito em diversos trabalhos por antropólogos, missionários e professores xavantes. Nesse artigo baseamo-nos nas seguintes referências: Maybury-Lewis (1984, p. 188-219); Lopes da Silva (1986, p. 64); Lachnitt (2003, p.88); e Xavante (et al, 2011).

2. As variações de grafia do termo Xavante obedece as seguintes regras: quando designa a etnia de maneira ampla, referindo-se ao conjunto das populações, dos costumes e/ou da memória, utiliza-se a norma da Associação Brasileira de Antropologia, sem plural e com inicial maiúscula; quando é utilizado para qualificar uma pessoa, atividade ou objeto, funciona como adjetivo, é escrito com inicial minúscula e pode ser utilizado no plural.

3. Cf.: < http://ti.socioambiental.org/pt-br/\#!/pt-br/terras-indigenas/3821>

4. A denominação Xavante é um etnônimo atribuído externamente, o qual foi assimilado e é utilizado hoje para lidar com os não índios, ou waradzú (extrangeiro). No entanto, sua auto-denominação é Auwẽ Uptabi (homens verdadeiros, povo verdadeiro), termo que também pode ser usado para referir-se a outros povos indígenas.

5. As aldeias xavante costumam ter o formato de um arco, composto pelas casas. No centro do espaço entre as casas, acontece diariamente uma reunião dos homens adultos da comunidade, para conversar e tomar decisões relativas a assuntos que dizem respeito à aldeia. O Warã é o espaço central da aldeia e é também o nome dessa reunião.

6. Os vídeos podem ser acessados pelos qrcodes ou urls ao longo do texto, que acompanham os respectivos frames.

7. Um dos resultados concretos do projeto foi a instalação em 2010 de um Laboratório de Produção Audiovisual em Software Livre, que chamamos de WederãLab. O laboratório continua funcionando e é gerido pela comunidade. Todo o material produzido a partir dessa experiência está sendo organizado para ser disponibilizado via internet no endereço <http://wederalab.blog.br>.

8. Hö é o nome dado à casa construída em um espaço separado do arco de casas que forma tradicionalmente as aldeias, onde os adolescentes irão morar juntos, separados de suas famílias, por todo o período de formação que precede a iniciação.

9. Imagem técnica é um conceito de Vilém Flusser, que se refere às imagens produzidas por aparelhos técnicos, e são resultado da abstração do mundo a partir dos conceitos científicos. Cf. FLUSSER, 1985.

10. No mesmo vídeo, Maurício ainda conta que alguns gostam de serem filmados, pois quando virem as gravações, anos depois, poderão lembrar-se do tempo em que "seu sangue ainda era forte", isto é, conectam-se, na velhice, com sua juventude por meio dos vídeos.

11. Como o são os indivíduos modernos, cindidos de suas comunidades, famílias e tradições de origem, guiados pela lógica do pragmatismo econômico, soltos no mercado, livres para chocarem-se uns contra os outros. O que não é o caso desses jovens, que possuem vínculos fortes tanto com seus ancestrais, que se materializam em suas memórias, quanto com suas comunidades.

12. No que se refere ao processo de esquecimento, é interessante notar que social e politicamente o esquecimento é o apagamento, a anulação das narrati- 
vas diversas em prol de uma que se toma como universal, justamente por se colocar como a única. Evidentemente, este processo não é natural, ou seja, não ocorre sem embates e é resultado de processos históricos e de conflitos entre grupos sociais. O obscurecimento das lutas, resistências e estratégias de reprodução social de determinado grupo atende a interesses específicos, que se beneficiam cultural e politicamente deste apagamento e da ideia de uma narrativa homogênea e universal. Esse processo legitima e reproduz um determinado fluxo de poder. É no âmbito do conflito cultural e político que se insere o trabalho com as memórias.

13. O Serviço de Proteção ao Î́ndio (SPI) foi um órgão criado pelo Estado Brasileiro em 1910, organizado pelo Marechal Rondon, para prestar assistência, proteger e mediar a integração e a co-existência dos povos indígenas habitantes do Brasil. Em 1967, o órgão foi extinto tendo suas atribuições transferidas para a Fundação Nacional do Î́ndio (FUNAI), órgão atualmente vinculado ao Ministério da Justiça.

14. Paulo Tavares (2012) em sua analise do papel da construção de Brasília na expansão da fronteira oeste como parte do projeto de modernização do Brasil, oferece uma interessante problematização do modo como nosso processo de modernização implica e, de certa forma, continua o processo de colonização do território. O historiador norte-americano Seth Garfield (2001) oferece uma análise aprofundada e bastante rica da relação política entre os Xavante e o Estado Brasileiro no processo de expansão de fronteira durante o período que vai de 1937 a 1988 e, portanto, englobando desde o Estado Novo até o período de redemocratização da Constituinte.

\section{Cf.: Estratégia Xavante (2007).}

16. O projeto Vídeo nas Aldeias foi idealizado pelo indigenista e cineasta Vincent Carelli e a antropóloga Dominique Gallois em 1987, como uma atividade do Centro de Trabalho Indigenista (CTI) de São Paulo. O projeto nasceu de uma atividade de produção audiovisual com os Nambiquara, e partiu da premissa de orientar o registro com finalidade produtiva, construtiva, em relação à identidade. Posteriormente, o projeto saiu do CTI e se tornou uma ONG independente, hoje sediada na cidade do Recife.

\section{Referências}

\section{Livros, artigos, teses e dissertações}

CAMINATI, Francisco Antunes. Terra incognita: liberdade, espoliação. O software livre entre técnicas de apropriação e estratégias de liberdade. Tese (Doutorado em Sociologia) Universidade Estadual de Campinas, Instituto de Filosofia e Ciências Humanas. Campinas, 2013.

DELEUZE, Gilles. Qu'est-ce qu'un disposif? In Michel Foucault. Philosophe, Rencontre internationale Paris 9, 10, 11 janvier 1988. Paris: Ed. Seuil, 1989.

FLUSSER, Vilém. Filosofia da Caixa Preta: ensaios para uma futura filosofia da fotografia. São Paulo: Hucitec, 1985.

GARFIELD, Seth. Indigenous Struggle at the Heart of Brazil: State Policy, Frontier Expansion, and the Xavante Indians, 1937-1988. Durham: Duke University Press, 2001. 
LACHNITT, Georg. Dicionário Xavante/português: romnhitsi' ubumro a'uwẽ mreme - waradzu mreme. Campo Grande: Missão Salesiana de Mato Grosso/Universidade Católica Dom Bosco, 2003.

LEAL, Samuel. Poder de criação: o uso social do vídeo em contexto xavante. $171 \mathrm{f}$. Dissertação (Mestrado em Sociologia com concentração em Antropologia) - Universidade Federal do Rio de Janeiro. Rio de Janeiro, 2012.

LOPES DA SILVA, Aracy. Nomes e Amigos: da Prática Xavante a uma reflexão sobre os Jê. São Paulo: USP-FFLCH, 1986.

MAYBURY-LEWIS, David. A Sociedade Xavante. Rio de Janeiro: Ed. Francisco Alves, 1984.

METZ, Christian. The Imaginary Signifier. Bloomington: Indiana University Press, 1982.

POLLAK, Michel. Memória, Esquecimento e Silêncio. In Estudos Históricos. Rio de Janeiro, v. 2, n. 3, p. 3-15, 1989.

SAHLINS, Marshall. "O Pessimismo sentimental" e a experiência Etnográfica: por que a cultura não é um "objeto em via de extinção". in Mana. Estudos de Antropologia Social. vol. 3, $\mathrm{n}^{\circ}$ 1, pp.41-73. 1997. Disponível em: <http://www.scielo.br/scielo.php?script=sci_arttext\&pid=So104-93131997000100002 $>$.

SHOHAT, Ella; STAM, Robert. Crítica da Imagem Eurocêntrica. São Paulo: Cosac Naify, 2006.

STRATHERN, Marilyn. 1999. Property, Substance and Effect: Anthropological Essays in Persons and Things. London: Athlone Press.

TAVARES, Paulo. 2012. Modern Frontiers: beyond Brasilia, the Amazon, in: Patricio del Real and Helen Gyger (Org.). Latin American Modern Architectures: Ambiguous Territories, New York: Routledge.

XAVANTE, Caimi Waiassé; XAVANTE, Leandro Parinai'a; XAVANTE, Severiá Idioriê. Cartilha escolar da iniciação dos adolescentes. Wederã: Escola Indígena Etenhiritipá, 2011.

\section{Filmes e vídeos}

Estratégia Xavante. Belisário Franca. 2007

Oi’ó: Luta dos meninos. Caimi Waiassé Xavante. 2009.

\section{Websites}

Instituto Sócio Ambiental - www.socioambiental.org

Wederãlab - www.wederalab.blog.br

Vídeo nas Aldeias - www.vna.org.br 
Recebido em: 07/07/14

Aceito em: 11/og/14

\section{SAMUEL LEAL}

\section{samuca.leal@gmail.com}

É mestre em Antropologia pelo Programa de Pós-Graduação em

Sociologia e Antropologia da Universidade Federal do Rio de Janeiro (IFCS-UFRJ). Atualmente é doutorando em cinema pelo Programa de Pós-graduação em Comunicação da Universidade Federal Fluminense.

\section{FRANCISCO ANTUNES CAMINATI \\ http://caminati.wiki.br \\ É doutor em Sociologia pela Universidade Estadual de Campi- nas (UNICAMP) e professor do Departamento de Planejamento, Urbanismo e Ambiente da Faculdade de Ciências e Tecnologia da Universidade Estadual Paulista "Júlio de Mesquita Filho" (UNESP - Presidente Prudente).}

\section{ALINE YURI HASEGAWA \\ É mestre em Sociologia pela Universidade Federal de São Car- los (UFsCar )e atualmente é doutoranda do programa de pós- graduação em Ciências Humanas e Sociais da Universidade Federal do ABC (UFABC).}

